\title{
Challenges and opportunities for teacher professional development in interactive use of technology in African schools
}

Hennessy, S., Haßler, B., \& Hofmann, R.

Faculty of Education, University of Cambridge, Cambridge, UK

For Capacity building for $21^{\text {st }}$ century learning in Africa: A focus on ICT integration in education. Special section of Technology Pedagogy and Education, edited by Jo Tondeur \& Joke Voogt, 2015, in press.

\section{Abstract}

This paper examines the supporting and constraining factors influencing professional learning about interactive teaching and mobile digital technology use in low-resourced basic schools in sub-Saharan Africa. It draws on a case study of iterative development and refinement of a school-based, peer-facilitated professional learning programme ("OER4Schools") that integrated use of mobile technologies, digital open educational resources and interactive pedagogy. The research and development involved teachers in three Zambian primary schools and culminated in an extensive multimedia resource.

Using an ecological framework, factors emerging were characterised at three levels: teacher, school, and the wider community and policy context. They include school organisation and leadership, teacher motivation and perceptions of opportunities for professional learning and change, teacher views of pupil capabilities, availability of resources, teacher collaboration, and viewpoints of parents and policymakers.

\section{Keywords}

1. teacher professional development

2. digital technology

3. sub-Saharan Africa

4. interactive pedagogy

5. Zambia

6. Open Educational Resources 


\section{Introduction}

This article explores the opportunities and challenges for supporting school teachers' professional learning about interactive teaching and digital technology use in sub-Saharan Africa (SSA). Buckler (2013) argues that teacher education has been a neglected area of policy development and several SSA countries did not have a national teacher education policy or strategy until as recently as 2007 . It has been proposed elsewhere that priority should be given to school-based professional development (PD), particularly "in developing world contexts where resources are stretched and where many people teaching in schools are unqualified or underqualified" (Moon, 2007: 356). Buckler's small-scale study of how rural SSA environments impact on teachers' ability to access in-service programmes (carried out as part of the Teacher Education in SSA or TESSA programme) indicates that this is endorsed by teachers themselves, who prefer not to travel long distances for courses and live away from families for long periods (Buckler, 2013).

At the policy level, emphasis is now firmly on educational quality and teacher professionalism in a bid to improve shockingly low literacy rates and attainment levels; the latest Global Monitoring Report asserts that "equitable access to well-trained teachers must be a policy priority" (UNESCO, 2014, p. 18). Yet in around a third of countries, less than $75 \%$ of primary school teachers are trained according to national standards, and training in many poor countries suffers from an overemphasis on theory rather than practice (ibid.). The report reveals that only $14 \%$ of the poorest pupils in low-income countries complete lower secondary school.

To raise educational quality and improve outcomes in SSA, it is increasingly clear that we need to begin to build capacity for $21^{\text {st }}$ century learning and teaching, and developing digital technology use can play an important role. Much research and development in the field focuses on integrating technology in education, although Power et al. (2014, p. 11) assert that "an understanding of the technologies as tools, used by communities, in the social practices of teaching and learning, directed towards educational goals" is paramount. The inhibiting factors they identified largely related to curriculum-based use of technology. Capacity building therefore needs to focus on supporting, resourcing (especially with high quality digital content) and raising quality of subject teaching, i.e. not merely integrating technology but triggering change in classroom practice. In our view, building pedagogical capacity in the SSA context (where technology provision is currently limited) requires programmes structured to exploit technology tools where available, but not being dependent on them. Such programmes do, however, create pedagogic conditions that enable the productive implementation of digital technologies when these later become available.

We draw on the research literature and our own experiences in Zambia over more than 4 years of iteratively developing, refining and evaluating a school-based professional learning programme, "OER4Schools," that integrates use of mobile devices, digital open educational 
resources and interactive pedagogy. Our observations and interviews have corroborated the usual constraining infrastructural and cultural factors of influence observed in SSA settings (Naseem, 2011). These include difficult circumstances for schools (e.g. lack of finances and teaching resources, lack of or unstable electricity supply, lack of running water, safety issues) as well as difficult working conditions for teachers, especially dearth of appropriate accommodation near the school, low and often delayed remuneration: Zambia has the sixth lowest teacher pay of all countries (UNESCO, 2014). These constraints are more pronounced in rural schools (Buckler, 2013) and teachers may feel disempowered and demotivated. High staff turnover and absenteeism rates (in both teachers and pupils) are common, and morale may be low. Even where teachers are keen to develop their own professional learning and their longer term careers, lack of opportunity for PD and practical obstacles are a hindrance (ibid.). In our experience, small, delayed salaries also mean that teachers need to take up casual work to supplement their income, resulting in less time available for PD or lesson preparation.

Further issues concern the nature of the PD itself and its alignment with existing curricula, policies and priorities, both within and outside the school. Previous research indicates that pedagogic interventions cannot simply be exported to new settings but require significant adaptation to local expertise, resources and constraints to inform practice (Bransford \& Schwartz, 1999). Our own studies (e.g. Haßler, Hennessy, \& Cross, with Chileshe and Machiko, 2014) have highlighted head teachers' view that specifically targeted teacher development opportunities for integrating both interactive pedagogy and technology use are an enabling factor. It has been argued that effective interventions should help teachers believe that they have or will have the capabilities and resources to use new technology, promoting coherence and commitment (Zhao, \& Cziko, 2001). Typically, new ideas and technology resources are assimilated into existing practices and beliefs, rather than teachers changing their practices to exploit the new ideas (Kennewell \& Beauchamp, 2007).

Research into teacher PD reviewed by Avalos (2011) and conducted over the previous decade provides some insight here. It includes a few articles scrutinising diverse forms of PD activities in terms of the dilemmas, conflicts and limiting circumstances that variously influence their effectiveness.

These articles highlight, for example, the dilemmas that facilitators and teacher participants have [when] promoting self-regulated learning, ... teacher tensions during activities due to competing responsibilities and pressures on their work lives arising from external expectations. . . and possible misalignment between motives or background of teacher participants in professional development and those of the responsible entities. Professional development geared to new curriculum implementation both assists the sharing of new knowledge with other teachers, but is also limited in terms of new pressures on their work lives by expectations of the program and the school district. (Avalos, 2011, p.13)

These pressures need to be managed. The school organisation influences the ease with 
which workshops and support networks can be put into place. In our studies, head teacher endorsement for interactive teaching - along with the time commitment it entailed - was viewed as crucial by teachers, other head teachers, and the researchers (Haßler et al., 2014).

While research evidence is limited, indications are that supporting factors include opportunities for modelling, classroom trialling, reflection and feedback. Guskey's (1989) theory of teacher change asserts that shifts in attitudes and beliefs generally follow - and are stimulated by - rather than precede, changes in behaviour. Hence, teacher development needs to be concrete, continuous and cumulative over a teacher's career, as in Japanese lesson study, which highlights the importance of teacher collaboration for PD purposes (Schwille \& Dembélé, 2007).

In contemporary models of PD including that underlying OER4Schools, teachers are construed as professionals, capable of critiquing and developing their own practice (e.g. Cordingley, et al., 2004). Reflective discussions thus need to support this critical selfexamination (Borko, 2004). Structured opportunities for thoughtful reflection need to emphasise understanding pupil thinking (Schwille, \& Dembélé, 2007). This means that teachers see teaching and learning as a two-way social process; an in-depth, rigorous review of 54 studies of pedagogical practice in low- and middle-income countries by Westbrook et al. (2013, p.63) found "a mutually reinforcing cycle wherein teachers' positive attitudes towards their training and their pupils lead them to employ interactive communicative strategies and practices which lead to learning in their students..." Critique and reflection also need to be collegial, focused on clearly articulated priorities, and related to opportunities to observe, experience and try out new techniques in their own classrooms (ibid.; OECD, 2005).

These supporting factors characterise PD programmes across the world, including SSA. However a learner-centred teaching initiative contextualised for Namibia encountered some issues; teachers had difficulty making the expected connection between theory in the materials and practice of the enquiry activities (van Graan, et al., 2005). Enquiry-based practice and developing skills for reflection are demanding and time consuming. Teachers may feel that implementing new pedagogy requires extra time (Carter \& Richards, 1999), both during and in planning lessons, and can distract from delivering their primary, curriculum objectives.

Where teachers are relatively new to the ideas and practices underlying reflection, active learning and enquiry, and unfamiliar with using technology in the classroom, a PD programme will be considerably more time consuming. To motivate teachers to attend, the programme therefore needs to be purposeful and clearly structured, with recognition of achievement, ideally leading to a certificate. Nevertheless, our studies indicated that mobile technologies - while not intrinsically transformative of pedagogical practice - are highly desired by both teachers and learners, and so can play an important motivating role (Haßler, Hennessy, Lord, et al., 2011). Our argument in this paper is premised on the notion that technology use can leverage a more interactive approach and a greater focus on learning. It moves away from the traditional view that technical skills should be taught first, without a pedagogically meaningful context for such 
use.

To conclude, with any PD programme in this context it is critically important to ensure that teachers are motivated and supported to participate as much as possible, in order to have any impact. Access to technology equipment (and telecommunication) and developing technical skills can be a powerful source of teacher motivation for participation in PD, but our experience is that wanting to develop one's own teaching practice can also arise out of professional pride, and from experiencing successful teaching, pupil engagement and learning gains. For these benefits to be realised, some of the infrastructural and other constraints outlined above need to be addressed; for example, while issues such as low pay are beyond the control of schools or those designing PD, programmes need to be creatively designed for low-resourced contexts and time needs to be allocated for participation. Effective and scalable ways of communicating new pedagogic ideas need to be devised. Further issues and proposed solutions are discussed in the report of our study below.

\section{Focus}

This paper draws on our experiences of designing, implementing, and evaluating a substantial PD programme aimed at developing more interactive teaching supported by digital technology use, together with Zambian stakeholders. Teachers' voices have been missing from much of the research and policy discourse (Buckler, 2013); they are foregrounded in our own work and the data presented here. We carefully took account of participants' views and backgrounds in developing, implementing and evaluating the programme. Our analysis drew on Tillman's (2006) account of culturally sensitive research to guide our understanding of Zambian classrooms, in particular to maintain a focus on soliciting and analysing Zambian teachers' own perceptions of supporting and constraining factors.

When research is approached from a culturally sensitive perspective the complexity of an ethnic group's culture, as well as its varied historical and contemporary representations, is acknowledged (Tillman, 2006, p. 266). ... Researchers rely on participants' perspectives and cultural understandings of the phenomena under study to establish connections between espoused theory and reality and then to generate theory based on these... perspectives ( $\mathrm{p}$. 271).

This perspective helped us to gather some insights from our teacher participants into their local culture and the school community - namely the established practices, experiences, values, resources, ways of thinking, prior knowledge and skill levels. Interview data was supplemented and interpreted through the aid of our own experiences over several years of working in the country and speaking to our school colleagues there. 
To mitigate the risk of forcing an inappropriate intervention, teachers' input into the programme organisation was sought wherever possible, and issues arising were addressed collaboratively. Suggestions made concerning content of the wiki materials were also taken on board and implemented in time for the next annual cohort.

The main research question addressed in the analysis presented in this paper was:

What supporting and constraining factors influence professional learning to promote interactive teaching and mobile technology use in low-resourced basic schools in Zambia?

This question was addressed from the perspectives of participating teachers, the school leadership, and the workshop facilitators. It included internal and external constraints, and questioning focused on soliciting concrete examples and suggestions.

\section{Description of programme}

\section{The current OER4Schools programme}

OER4Schools is a multimedia PD programme designed to offer teachers in English-speaking SSA new, sustained opportunities for peer learning, adapting the established principles of effective PD to a new context. The complete resource is available at www.oer4schools.org, together with background information. The workshop-based programme and its underpinning cycle of stimulus, reflection, lesson planning and classroom trialling are also extensively described by Hennessy, Haßler, \& Hofmann (forthcoming).

OER4Schools goes beyond technology- and skills-focused initiatives by highlighting the crucial role of teacher support in promoting innovation and experimentation with teaching styles. The programme supports active, collaborative learning of mathematics and science - generally, and through using mobile technologies (tablets, netbooks, e-book readers etc.) where available, along with digital Open Educational Resources (OER) and Open Source software.

The materials include unique, professionally filmed video exemplars of interactive practices in Zambia and South Africa. The six units in OER4Schools cover interactive teaching principles, group work, questioning, dialogue, Assessment for Learning, enquiry-based learning, and communication with other stakeholders. There are 25 two-hour sessions in total, which roughly provide a year-long programme (if sessions are run weekly). The material has scope for adaptation to teachers' own purposes and settings and explicit encouragement for facilitators to respond to issues arising. Each session features educator notes in shaded boxes interspersed with the main text, providing additional guidance to the peer facilitator. All activities relate to topics 
in the current Zambian curriculum. Each session also features an activity practising technology use, that is very closely tied to classroom use, rather than teaching about technology for its own sake.

The programme was co-developed and locally contextualised by Zambian teachers and other local partners, who provided valuable input throughout the creation and refinement of the OER4Schools resource. This resonates with the observation by Mubanga (2012), Director General, Zambia Ministry of Education, that knowledge needs to be actively acquired by participants, importance needs to be placed on local values and expertise, and existing capabilities need to be drawn upon. Our overall approach to "quality" is framed by the principles of social justice (Tikly and Barrett, 2011) emphasising participation and voice, focussing on the enabling school environment in Tikly's (2011) context-led model for conceptualising educational quality. As conceptualised through the Zambian "School Program of In-service Training for the Term" (SPRINT) programme which seeks to initiate sustainable CPD, including teacher group meetings, OER4Schools responds to the need for cost-effective, large-scale development opportunities for teachers (with a pedagogical emphasis). The OER4Schools programme partly achieves this through the use of OER, and embodies the OER freedoms (legal, technological/access, participation; Haßler \& Mays, 2014 ), which are related to the wider discourse of 'open development' (Smith et al., 2011). The programme shares a similar outlook with other OER initiatives for teachers like TESSA (www.tessafrica.net) and OER Africa (www.oerafrica.org), but is unique in that it is the first open, structured and sustained (year-long) programme, which teachers can follow systematically.

\section{Overview of Phases 1 to 4}

Data collection during the research programme was primarily conducted by the first two authors and two Masters students (one each in Phases 1 and 2). An overview by phase is given in Table 1 .

The (pilot) Phase 1 assessed the feasibility of supporting interactive forms of subject teaching in conjunction with providing OER to computer- and Internet-equipped primary schools in Zambia (Haßler, Hennessy, \& Lubasi, 2011; Hennessy, Haßler, \& Mwewa, 2012). It was initiated in 2009, in response to a project led by an NGO partner in Zambia, iSchool.zm, who were integrating technology into Zambian schools with limited pedagogical support at the time. Our aim was to identify and respond to the needs of school-based PD adapted to the local context, as identified by iSchool and their school partners. In Phase 1, we worked over a 6-month period (January - June 2010) with eight experienced teachers in three basic (primary) schools in Lusaka province, all serving under-privileged communities.

Our Phase 2 (October 2010 - October 2011) work involved only two of the original schools for capacity reasons, with two teachers from each school moving forward. The first stage involved preparation in the UK and remote communication with the teachers, supporting 
them in developing interactive pedagogy. The second stage focussed on the iterative coconstruction of concrete lesson plans (between Zambian teachers, lecturers, and UK-based researchers) that promoted interaction and collaboration supported by technology use.

Those stages in Phase 2 also benefited from the parallel DfID-funded Appropriate New Technologies to Support Interactive Teaching in Zambian schools project (ANTSIT, October 2010 - April 2011, see Haßler, Hennessy, Lord, et al., 2011). The research explored what kinds of mobile devices and innovative uses can create an environment supportive of learning through active participation in under-resourced school communities. The grant provided a small number of mobile devices and non-digital resources.

The third stage of Phase 2 capitalised on these outcomes. We worked with a professional film producer to record two lessons each with three teachers. Again, there was a 3-month period of attempted remote communication beforehand, and then in-depth joint lesson planning and review immediately before and after the filmed lessons. Our ultimate aim during this stage was to create a multimedia professional learning programme, described below. Phase 2 is elaborated by Haßler et al. (2014).

In Phase 3 (school year 2012), the programme involved only one of the original schools, and was facilitated by two teachers moving forward into this phase (one as facilitator and the other later on as co-facilitator), working with peers. Chalimbana Basic School (CBS) (Chongwe, Zambia; an hour east of Lusaka), the main research school, is a mixed sex Government primary school with around 35 teachers and about 1,000 pupils (Grades 1-9). It is poorly resourced and serves a predominantly disadvantaged community; many children are orphaned or otherwise vulnerable. Phase 3 involved 12 teachers (all Grade 4-6 teachers) with varying levels of professional experience and qualifications, engaging with the programme on a near-weekly basis. Teachers (and pupils) had little prior experience of technology use (except those teachers and pupils who had participated in earlier phases), apart from some personal use of desktop computers. Participation in the research study was voluntary for the teachers and pupils, and explicit written permission to gather evidence for the study was obtained before any work commenced. The OER4Schools collaborative resource development continued in parallel with the trial, with facilitators reviewing and providing feedback on new materials, as well as lessons learned from the earlier parts feeding into the development of later parts, leading to a complete draft version by October 2012.

In Phase 4, OER4Schools was spontaneously launched by CBS as a whole school programme in January 2013, involving 35 teachers across Grades 1-9. It was agreed to move to bi-weekly teacher group meetings, to reduce the load on teachers, which means that the programme is continuing until the end of 2014, as an ongoing 2-year trial; peer facilitators are leading colleagues through regular teacher group meetings using the resource. The resource was further developed and revised throughout 2013 in response to teacher feedback. Our research questions across Phases 1-4 included: What forms of stimulus and support are most effective in 
developing more interactive pedagogy? What changes took place? What were the supporting and constraining factors? The final question is the subject of this paper. First, we outline the technology used and then summarise the changes observed to take place.

\section{Technology tools and resources used in the OER4Schools trials}

Importantly, the OER4Schools programme can be run with varying levels (and different types) of technology provision, as well as without any, whilst laying the pedagogic ground for subsequent integration of digital devices. The main research school, CBS, had mains electricity but little functioning technology when the OER4Schools programme was first piloted there in 2009. There was a computer room with outdated and non-functioning desktop PCs; this is typical in SSA (Hennessy et al., 2010). For the second phase of the programme, we had already made 8 pupil netbooks available, as well as some additional low-cost teaching resources (such as miniblackboards, measuring tapes, some calculators, and a cheap digital camera). For the third phase this number was increased to 12 with research funds, and we set up a teacher lab with four laptops. The number of netbooks meant that, with children working in groups of about 4 per netbook, each student had about 1.5 to 2 hours of shared access, per pupil per week. The choice of netbooks over tablets (the latter were also trialled in one school during Phase 2) concerned affordability, robustness, and the availability of Ubuntu-based software and compatible educational applications at that point in time (2012).

We also introduced a hand-washing routine around the use of the equipment. We felt that this would help encourage a respectful approach towards the equipment, but would also encourage hand cleaning (with soap) — widely advocated as a disease prevention measure, while facilities are often missing.

For the teacher lab, we commissioned a square table from a local carpenter (with a central hole for cables, including power and Kensington locks), wide enough for four larger laptops (15" screens), with space for additional resources and pair working at each screen. We also provided a laser printer, so that resources for the teacher group sessions could be printed.

A local Wi-Fi network (using Nanostations) linked netbooks and laptops to each other, and to a central (low power, high resilience) server. The server provided a number of facilities, such as locally-hosted resources, including a PXE-boot based way of restoring netbooks to the default configuration, as well as a "dropbox" allowing teachers to store their files on the server and access them from any teacher laptop, or for pupils to access files during lessons. This facility was also used to upload audio reflections (as .mp3 files) and images, for retrieval by the researchers. A fast Wi-Fi connection to the local server allowed teachers to conveniently upload materials for sharing, without accessing the internet. The server also acted as a gateway for the teacher laptops to connect to the internet (via the very small aperture terminal [VSAT] of the 
adjacent college). This very slow and intermittent connection did allow teachers to browse the internet and to download resources for offline classroom use. It was not technically feasible for the classroom netbooks to connect to the internet directly. The connection also allowed the retrieval of research data by the researchers in the UK.

The OER4Schools resource draws on a number of computer-based "core" activities, that are applied to suit various learning objectives and topics throughout the programme and across the curriculum. Such "core" activities include writing (in OpenOffice, or collaboratively with EtherPad), spreadsheets, image manipulation, mind maps, and (importantly) GeoGebra, all based on Open Source software and OER. Rather than overloading teachers and students with a large range of bespoke, "closed apps" with restricted curriculum use, we choose to use a range of "open-ended" interactive applications, enabling teachers and students to develop familiarity and expertise. Note that teachers and students are not introduced to the technology via demonstration and rote learning, but through enquiry-based explorations.

The well-established issues pertaining to the use of technology in developing countries, such as lack of resources, security, poor connectivity, power outages, limited battery life, other technical issues and maintenance (Hennessy et al., 2010, p.121) applied in our context too, as expected. Some such challenges were mitigated, however, as the programme progressed and some teachers learned to overcome these constraints, and support other colleagues in doing so. For example, they instigated a daily charging routine under pupils' responsibility, to ensure that netbooks were charged and ready for use in class. They also ensured that resources were downloaded when there was connectivity, in order to be able to use them offline. Details are described in previous papers and reports (eg. Haßler et al., 2014; Haßler et al., 2011). Findings related to PD (across all phases) are the subject of this paper.

\section{Findings pertaining to changes in classroom practice}

Throughout the four phases, the teachers in our studies were gradually coming to grips with novel technologies and developing an interactive teaching approach. Thus we inevitably needed to provide substantial support over time - initially face-to-face through post-lesson discussions and workshops (Phases 1-2), and then through the multimedia resource and structured PD workshops (Phases 3-4). Our conclusion was that under these conditions some engaging and pedagogically interactive lessons can take place, although quality of the final outcome could vary.

During the 1-year trial in Phase 3, and corroborated by interviews in Phase 4, teachers developed greater motivation through the programme and employed interactive strategies, seemingly leading to pupil learning (Westbrook, et al., 2013). Specifically, they were found to have raised their expectations of pupils, adapted to their knowledge levels, used a range of interactive techniques, especially practical and group work, integrated technology use, and collaborated with peers. Learners built deeper understanding of subject matter, were more 
actively engaged and motivated, collaborated with each other, and using digital technologies for problem solving. (See Hennessy et al. [forthcoming] for details.) Teachers were ultimately able to teach interactive lessons, including a degree of improvisation to address challenges (Haßler et al., 2014). Our findings confirmed that PD opportunities are essential for teachers to make creative and pedagogically interactive use of new technologies.

Our empirical work, informed by the research literature, has led us to arrive at a number of guiding principles for in-school PD in this and related contexts (ibid.). These include face-toface opportunities supporting learning from and with mentors and colleagues through reflective dialogue and critique of practice; a focus on classroom trialling and pupils' learning needs; culturally appropriate and sustained development opportunities that accommodate concerns and constraints of teachers and the school environment. These principles underpin the OER4Schools PD programme and constitute potentially supporting factors for PD aimed at interactive teaching with technology in SSA.

In addition, findings specifically relating to mobile technology use (partially derived from ANTSIT, see above) elicited supporting factors for such a programme. For instance, mobile devices (netbooks, laptops, tablets) are used successfully with non-digital tools, such as measuring tapes, counters or stones, stopwatches, rulers, and particularly with miniblack/whiteboards for recording and used as "showboards" after individual or small group work. Non-digital tools are inexpensive and can be ubiquitous in a school for a fraction of the cost of a technology installation. A sole focus on mobile technologies in PD is thus unhelpful.

\section{Methodology}

\section{Data Collection}

The data used in this paper predominantly derive from semi-structured interviews with teachers and senior leaders at CBS, as well as some workshop recordings, with the bulk of results deriving from Phases 3 and 4. The participants were as detailed above. There were a number of interviews conducted in 2012, and additional interviews in 2014, in various groups according to the time they joined the programme and their role in the programme. Additional questions were introduced in each phase (see Table 1), while questions for teachers were standard across grades and schools within each phase; variations were used for facilitators and school leaders. All interviews were accurately transcribed. The workshops recordings were reviewed and either partially or fully transcribed. We note that transcribing the more lively workshop discussions presented a challenge because of several people talking simultaneously. Most data comes from sources in the table; additionally a number of post-lesson meetings and ongoing informal discussions informed our understanding. 


\section{Data Analysis}

\section{An ecological perspective}

Davis' (2010) review of the diffusion of digital technology innovations in education from an ecological perspective construes the teacher's classroom as the central ecosystem within the school (another ecosystem), nested within the region or nation. This view portrays change in the classroom ecosystem as likely to impact related ecologies, and conversely, lack of change in the organisational ecologies may impede change at the classroom level. Change is complex and the ecosystems evolve in unexpected ways (ibid.), with planned innovations likely to have unintended consequences, so needing to be monitored and continuously adjusted as the systems attempt to maintain equilibrium (Somekh, 2010). Recognising this, we characterised the opportunities afforded by the programme and the (related) challenges/constraints on several 'levels': (a) teacher, (b) school, and (c) the wider community and policy context. These levels shaped our data collection through suggesting different perspectives to investigate, particularly in terms of soliciting views about supporting and constraining factors at each level during interviews, from all participants: comments from teachers and head teachers span the three levels, of course. The levels are used as an organising framework for the Findings.

\section{Analysis procedure}

Analysis was conducted by an independent researcher (the third author) who had not previously been involved in the project. Initially the data was scrutinised to identify general themes and areas of rich content as well as emerging puzzles and speculations to be tested further. Categories of relevant content were formed and refined and these were used in a second round of coding to apply them across the data set. The qualitative data analysis software NVivo was used to assist and to run further reliability checks through in-built text and coding queries. Selected data were coded twice to further ensure the robustness of the coding. The groundedness of the categories was explored prior to interpretation by systematically examining the spread of the discussions across the participants and data sources.

The focus of the analysis was on constraining and supporting factors influencing implementation of a professional learning programme for interactive and mobile digital technology use in SSA. A central strategic approach was examination of issues/data across

- time (early and late interviews);

- people (examining similarities and differences in different teachers' views), and

- communicative settings (interviews and workshop discussions)

to explore the strengths and weaknesses of the emerging argument. 
As the discussion of the findings below illustrates, in this process discrepant as well as ambiguous cases were systematically examined. Each aspect of the emerging argument, together with supporting and contradicting data, was then discussed and scrutinised for reliability and validity.

\section{Findings}

Teachers in SSA face many challenges and hardship in their daily lives. Our focus here is on examining these challenges from the particular perspective of their influence on opportunities for professional learning and pedagogic change. We include the supporting factors that can address the challenges for teachers' continued engagement with professional learning.

\section{Teacher-level factors}

\section{Teachers' perceptions of their professional learning needs and the motivating role of technology}

One of the challenges of supporting professional learning in any context is meeting professional learning needs that teachers in that setting perceive themselves as having. At the beginning of the OER4Schools programme the participating teachers suggested that they were already familiar with the ideas of interactive teaching from their college courses. Some initially considered the novel aspects of the programme to relate simply to technology use.

MARTHA (2 months in): The only difference [from before] is that pupils also can do interactive teaching [learning] using the netbooks. [Reiterates later:] We were doing group work, though we didn't realise that this is another way of . . . 'interactive teaching'. We just had another name.

Some teachers acknowledged that the pedagogic ideas of the programme were not necessarily being implemented in their classrooms.

PRISCILLAH: So far (2 months in), we [already] did most of the things that we discussed in the programme, yes. Except we don't practise what we are taught in colleges.

The workshop facilitator also suggested that the underpinning ideas are in principle familiar to the teachers but only in theory: “it's more like we are building on what we have already acquired and maybe forgotten" (Abel).

As we have discussed in detail elsewhere (Hennessy et al., forthcoming), having actually engaged with the PD programme, there was widespread recognition among the teachers that previously interactive teaching had not actually been the norm, even if pupils were, for example, 
seated in groups. For instance Martha suggested at the start of the programme that she had already been engaging her pupils in interactive teaching and interactive group work (see above). Towards the end, she reflects:

MARTHA: This programme has been a revival in my teaching. ... Because in the past ... if you are lecturing, you don't even give the group work.

Other teachers' comments resonate with this acknowledgement.

AGGIE: Maybe we are doing it just on the surface, but after doing this [OER4Schools] we were really deep into it and even knew how to ... really involve [learners], because in Zambia we are saying lessons should be pupil-centred. But ... sometimes we say, this topic is too hard for the pupils, I cannot just leave them to do it alone.

While the teachers gradually came to see the added value of the PD, this points to a potential constraint for PD programmes that may apply more widely. Our analysis suggests that there is a commonly accepted discrepancy between teacher education and professional practice among teachers; it is not perceived as necessary - or even possible - to implement ideas learned during training, but never observed in practice (before encountering the OER4Schools videos). This may pose a challenge for engaging teachers in PD. It may thus be that meeting teachers' learning needs is not a fixed starting point for a programme but a process, one that in itself involves professional learning. This was reinforced by the workshop facilitator when asked about whether the programme corresponds to the teachers' interests and needs at present:

ABEL: With time I think it will. At the moment (2 months in), |I wouldn't say much because. . I'm sorry to say this, but most of them are thinking interactive teaching is all about ICT.

One supporting factor that clearly led to motivation of teachers to engage in this PD programme, then, was related to digital technology use. These teachers had previously had limited opportunities to use and learn about technology. Their motivation was not solely related to their own skills but to their pupils' skills for future use: "this world now is going technology all over" (Martha). Some mentioned use to support classroom learning, for example "researching the pupils' work" (Mirriam), and the observed excitement of children (who "didn't even have TVs at home") encountering computers (Susan).

\section{Teachers' perceptions of pupils' capabilities to engage with the programme ideas}

TEACHER [IN A WORKSHOP]: It is supposed to be child-driven but that depends on the type of children that one has, if they are able to organise themselves, to make sure that learning takes place, not like our children.

This quote and the earlier one by Aggie (5.1.1) illustrate an initial feeling among the teachers in the school that 'their pupils' are not capable of learning interactively. In the late interviews the teachers discuss extensively and with concrete examples the ways in and extent to which their perceptions of their pupils' capabilities have shifted during the programme, to their surprise; they 
acknowledge that they used to systematically underestimate their pupils prior to participating in, and trialling, the new pedagogies and tools (Hennessy et al., forthcoming). Judith describes and illustrates this:

\footnotetext{
Before I used to underrate children saying that I got to keep on lecturing. . . . I ask[ed] questions to say "what about this?, what have I said here?", without giving them a chance to think on their own before I could summarise everything. But after this programme, I first tell them what. . . I expect to get, the objectives.... So on their own they are able to find answers and thereafter tell them to me.

They were doing some activities, of measuring how much fats each one has. I couldn't believe it, ... I was really surprised because they were able to weigh themselves, write the kilograms for each one, because we are doing it in pairs so that one weighs the friend, then also the height. And then they were able to multiply the height of somebody to square it, and then divide into their weight. [See http://oer.educ.cam.ac.uk/wiki/Video/Judith_body_A06.m4v].
}

The same lesson also involved the use of spreadsheets to calculate and record body mass index [see http://oer.educ.cam.ac.uk/wiki/Video/Judith_Body]. The issue of low teacher expectations - and the surprise about pupils' capability to learn quickly - also pertains to pupils learning about technology use. Teachers are usually adamant that pupils need to be taught about hardware before they can make use of it. Learners perceived as poor are particularly expected to have difficulty in learning with technology. However, expectations were not realised and technology has come to be perceived as a leveller.

AGNESS: The first time, I wondered if the ones from villages will know what this is ... To my surprise, after [using the computers] three times, before I could even tell them to . . they were there, switching it on.

This quote refers to a netbook familiarisation activity conducted early on in the programme [see http://oer.educ.cam.ac.uk/wiki/OER4Schools/Introduction_to_interactive_teaching_with_ICT].

However, at the stage of introducing PD, the teachers' perceptions of pupils' (lack of) ability to engage with the programme can be a core constraint. If the pedagogic ideas are not seen as feasible, teachers may be less likely to engage in professional learning. On the other hand, the danger of PD programmes, as we have discussed earlier, is that ideas are taken up in a way that merely assimilates them to current practice. We suggest that teachers' understandings of the ideas also warrant attention.

\section{Teachers' understanding of new pedagogic ideas}

The new understandings of pedagogy that emerged during the teachers' participation in the programme did not happen immediately or automatically. Effectively communicating new pedagogic ideas is another challenge for supporting professional learning.

The convoluted workshop discussions that illustrate some of the teachers' struggles with understanding the ideas are difficult to present briefly. We illustrate this issue through an exchange between two teacher-facilitators in one of the workshops in which Abel appears to be 
suggesting that Agness does not quite understand the ideas of enquiry-based learning as promoted by the programme. As with other ambiguities and misunderstandings arising in workshops, he attempts to clarify this to all participants.

In the extract below the teachers have worked in groups to design concrete outdoor activities for the children based on the principles of enquiry-based learning and are now discussing those ideas and plans together. The workshop facilitators first remind the participants of the importance of making plans that can actually be realised and ensuring they are well received by colleagues. Moreover, they emphasise the importance of considering the pedagogic principles at play and pupils' learning.

AGNESS: You can end up making a field trip just for leisure if you are not careful. [But] if you plan, you can make sure you are going to plan something which the pupils are going to use, remember, it's enquiry-based learning. Where they are going to learn something.

They then move on to presenting the concrete plans the teachers have developed. One of the workshop facilitators again highlights the core pedagogic issue of the task and its conceptual challenge:

ABEL: If we are to look at what you have developed there, your plan. Let us ask ourselves this question as they are ending their topic: Is what we have developed, is it enquiry-based learning?

He evaluates it as not having sufficiently embraced all the principles of enquiry-based learning:

ABEL: I think this one is enquiry-based because it involves the learners going out there to find out, except, how you're going to be questioning them, are they going to be deep questions, are they going to be thought-provoking questions. What type of questions can you be asking?

The other facilitator, Agness, elaborates on the project plans and Abel points out superficiality and weaknesses, clarifying how the proposal falls short of the principles of enquiry-based learning and how it could be enhanced.

AGNESS: Pupils will go out there and collect different types of plants ... then after collecting they will start naming the plants they've collected if they are similar or different. After that, they even draw the plants they've collected, then the assessment will be done by the teacher.

ABEL: The types of questions you will be asking, are they going to be open-ended?

Abel elaborates on his critical challenge and Agness builds directly on his idea:

ABEL: I think it's not enquiry-based . . . if it is classified as plants. But if you put it in a way [that classifies] flowering and non-flowering it becomes more interesting. They will want to see and know which one...

AGNESS: 'Why is it not a flowering plant?'

This excerpt illustrates how new pedagogic ideas offered for professional learning are not 
necessarily taken up by teachers in a way that offers the potential to impact on their current practice in intended ways but that this requires sustained effort and support. Another example for this was the use of "traffic lights", an Assessment for Learning technique to indicate progress during group work, which was sometimes used as a tool for voting instead.

This also illustrates the potential key role of workshop facilitation in mediating the teachers' understanding of the pedagogic ideas, their feasibility, accessibility and practical application. The following workshop extract from a session where teachers identified PMI (positive, minus, interesting) aspects of each of four kinds of enquiry reinforces the importance of supported, practical activity for grounding complex ideas. The workshop facilitator, Agness, links the difficulties children experience with traditional teaching to the teachers' own difficulties with professional learning.

A TEACHER: When we were discussing ... we felt it was very complicated ... what is involved in each type of enquiry. But, when we did it, we found it to be interesting.

AGNESS: And that's when we understood that part. So, it shows, that even in class, once you, as a teacher, just talk, talk talk, some pupils will just be left in a dilemma but once you give them an activity to do I think they will understand better.

Developing confidence to both try out new techniques and use new technologies requires a 'leap of faith' as one teacher described it. We suggest that our analysis of the three constraints discussed thus far further suggests that immediate opportunities for trialling new, promoted pedagogic ideas in practice in their own classrooms appears to have been central to enabling and supporting teachers' understanding of the pedagogic ideas and their pupils' capabilities of engaging with them. The teachers also came to perceive differently the communities they serve and, ultimately, their own capabilities - a central achievement of professional learning, as Agness elaborates.

AGNESS: I've changed ... I know how to form groups, I know how to give different tasks to the children at the same time, and by so doing, I cover a lot within a short time. I know how to use this ICT with my class ... especially where Etherpad is concerned, [concept] mapping is concerned. So, I've really changed. I've really improved. I know how to download from the internet.

A number of video exemplars that show teachers use netbooks in class (as mentioned by Agness) are available on the video collection for the resource [see http://oer.educ.cam.ac.uk/wiki/Video].

\section{School level}

\section{Resources as a challenge and a motivator}

There are also many system-level factors influencing the possibility of professional learning in this school setting. One central challenge these teachers face in their daily teaching is scarce resources. The teachers' professional learning about technology use was constrained by limited 
access to computers and technical support, both in their classrooms and in the teacher lab facilities, which limited the time they could spend familiarising themselves with the technology dimension of the PD programme.

The financial situation of the school was perceived as a further constraining factor; teachers mentioned lack of money to take pupils on field trips to try out ideas from the programme in practice. However, physical teaching resources can also be constructed in the school context by sufficiently motivated teachers. Resources available include furniture and teaching resources (paper, pencils; books, posters, mini-blackboards), as well as computers.

At the same time the analysis suggests that the teachers' engagement with the programme itself enabled them to find novel ways of dealing with some of the constraining factors, such as limited access to rich teaching and learning materials supportive of interactive pedagogy:

PRISCILLAH: As a teacher, you have to be resourceful. That's one thing I also learned from OER4Schools. So, even where we don't have enough materials in the school, I should learn to improvise, you know, there are so many things that I can use, to come up with.

This is not a complete solution:

PRISCILLAH: Certain materials are difficult to improvise, so it really made me not carry out certain experiments.

But it is a start. The introduction of mobile digital technology use in the PD programme provided further support as it enabled teachers to access information and materials online that would otherwise not have been available to them, and simultaneously developed their teaching capability.

PRISCILLAH: I thought if. . . I incorporated ICT in my interactive teaching, it was going to bring more benefits, not only to me, but ... to the learners that I teach. For example, there are times when you have limited resources. Now, in the situation where you have ICT, in school, like we have the internet, I would simply, quickly rush to the internet and check for information. . . Not just what we have in school but getting more and also broadening my own understanding, as a teacher, so that I can teach interactively.

Similarly, when the teachers spoke about lack of money inhibiting them from taking the pupils on field trips, Abel, the workshop facilitator, suggested they think more creatively about the environment they are already in and the potential for learning outside the classroom it may offer.

ABEL: I think when planning for your project.... So, as a teacher, you need to look at the environment. What things are around us, what topic can I teach, using the resources within the environment.

Our observations of enquiry activities indicated that the teachers came to make use of their local environment for enriching pupils' learning.

We suggest that these affordances can be considered as latent supporting factors of the PD programme (Rainio \& Hofmann, 2015). The PD programme facilitated and framed the 
discussions and infrastructures that made these new creative ways of thinking and action possible but they only came into being through the teachers' own active engagement with the programme. The same applies to another emergent supporting factor, collaboration with colleagues.

\section{Collaboration with colleagues and emerging supporting factors at school level}

There was one resource that we suggest is a central supporting factor for professional learning, that is available in any setting, however impoverished: colleagues. We have already illustrated above how discussions with colleagues and teacher facilitators in the workshops mediated teachers' understanding of programme ideas and allowed them to test out new techniques and ideas. A common theme in the data is how informal collaboration with colleagues helped to develop teachers. Early on in the programme, Mirriam, when asked about the most significant changes in her practice so far (March 2012), mentioned more interactive learning and teaching in her classroom and increased support for and from other teachers.

MIRRIAM: Pupils are learning interactively . . . And then, as teachers, we are able to consult each other: 'oh, on this point, what can I do?' 'How can I go about this lesson?' We consult among our group. Yes. . . . [Both outside and] during the workshops. Because, we even do some observation, especially Martha. Because we are neighbours ... so when Martha is teaching, I go there, I observe when she has the problems, I help her. She also comes to my class.

Martha (and Judith) corroborated this, adding "That way you find I have even improved my interactive teaching".

There is potentially a productive cycle whereby increased collaboration with colleagues may support the teachers in the implementation of pedagogic changes and dealing with the challenges described earlier. Having the support of a colleague is constructed in these accounts as enabling a teacher to see what they could do differently, take risks and try implementing new practices. However, the shortage of staffing resources constrained their access to this support, as we explain below.

\section{Organisational challenges for implementation of PD}

The organisation and timetabling of teaching clearly influenced the implementation of the PD programme. It was perceived by teachers to constrain their professional learning and capability to draw on the above discussed emergently identified resources.

The teachers have stated that interactive teaching requires in-depth planning and reflection, and "spending a lot of time on research" (Doreen). In the lesson itself, increased interaction and feedback mean that lesson plans sometimes do not get completed ("There's a lot of interference in the progress of the lesson": Sydney) and differentiation now means more time commitment too ("you find [some pupils] are lagging behind you, and you want to bring them to the same level": Clive).

As teachers increasingly emphasise learners' understanding, previous practices are de- 
emphasised (such as going through the motions of completing the formal syllabus), and this in turn means that backing from the head teacher is needed.

CECILIA (head teacher, CBS): The pupils weren't conversant with the computers, so the teachers were taking a lot of time to teach one concept [and] not covering all the subjects that we teach in a day.

The time needed to attend workshops, study the materials and trial the new ideas in their classrooms was also perceived as a central challenge by the teachers that limited their engagement. Teachers highlighted the competing priorities they faced, either at school level (e.g. running clubs) or at national level (e.g. introduction of new primary curriculum in Zambia).

One facilitator described how it was important to maintain motivation and momentum with regular meetings but facilitators needed to prioritise material in order to fit it all in to the time available: "We can be skipping those [readings], but look at the very important and very new things to the teachers" (Abel).

A supporting factor is that the OER4Schools programme fits neatly into the abovementioned Zambian government's SPRINT framework, which seeks to encourage sustainable PD (Mubanga, 2012), primarily through regular teacher group meetings scheduled within the school day. (Teachers at the main research school teach only half of the day - which is officially 8 hours long - whereas teachers in another of our schools taught double shifts of pupils, so it was harder for them to participate). Both the head teacher and facilitator reported that teacher attendance was not full and considered that participants' reasons were often domestic issues and sometimes insubstantial.

An interesting challenge raised by the teachers was the potential misperceptions of colleagues and school leadership of their novel activities during the programme (cf. Avalos, 2011, p.13). Teachers felt that their leaders did not understand the role of "educational noise", although head teacher Cecilia confirmed her understanding that "where there is interactive teaching, the class is noisy". Teachers also worried that colleagues would think they were being lazy or 'wasting time', when conducting enquiry activities outdoors, and stressed the importance of informing administrators.

\section{Wider context: Community and national level}

\section{Community level: Pupils' backgrounds}

Perceptions concerning 'the type of children' the school has are discussed in the data as constraining factors for pedagogic change. These impinge on the perceived value of and opportunity for professional learning (for example one participant describes giving pupils written formative feedback on their learning as a 'waste of time' since their kind of pupils 'won't read it anyway'). Likewise, parental support was inconsistent and some children received little: 
PRISCILLAH: A child would [often] come to school without homework being done. Parents don't even care.

Some of the constraints relating to pupils' backgrounds and communities concern issues that are difficult for PD programmes to impact on. Beside lack of parental support, these involve poverty, hardship, bereavement and living a long distance from school. At the same time it is worth noting that there is some evidence from our study that the participants perceived the opportunities for professional learning, new pedagogic ideas and use of digital technologies together as also offering at least partial support in dealing with these challenges. Some of the teachers suggested that pupil absenteeism had reduced due to learners' enthusiasm for the project, particularly the opportunity for digital technology use. Pupils were described as 'excited' (Bernadette, Susan) and several suggested that participation in class had significantly improved (e.g. "those previously not speaking, are active participants now": Priscillah).

While policy advocates use of local language (particularly in lower grades), and many children do not speak English well, it is nevertheless widely used as a medium of instruction. We found that children tend to switch to local language for discussion during group work, which helped children with weaker English skills catch up. Thus code switching was encouraged within the programme.

Some of the teachers also reported shifts in thinking with regard to the children's communities and better understanding the knowledge that these communities have and its potential value for education.

JUDITH: I did the activity of where pupils went to the community to find out how HIV/AIDS is being spread, and how it can be prevented. I said "you go, you find out". The other groups went to find out how it can be contracted, find out from the people around. The others went to find out how it can be prevented. And they came up with the answers. So to me, it proved that answers they are all over, even the community can come in, it will help with teaching the children, it's not only the teachers . . . we are all learners. We can learn one or two from the community as well, even from pupils. There are certain things that pupils know which we don't know.

There is even some evidence of a reciprocal shift in parental attitudes, turning a constraint, at least in some cases, into a source of support.

DAVID (head teacher): [Parents'] concern is that at the end of the year their children will fail the government exams.... So there are some who are asking [me] questions; but of course after being taught the value of what is happening - that it's helping their children to fully understand and to be more acquainted with what is happening now in the world - they understand and they appreciate and they recommend. That's why I told you that last year we had more Grade Ones who entered the school. . .because the parents saw the difference - what the school is doing in the community. [....] So the interaction that the parents have given, that is a very big supporting factor.

\section{National level: Perceived risks and challenges}

Finally, one consideration for PD programmes in any setting is their compatibility with national policies and requirements, including curricula and school inspections. This can pose a particular 
challenge in SSA settings where national policies are not always internally consistent or clearly communicated to schools; documentation can be elusive or misplaced. However, our analysis demonstrates that beside endorsement by policy makers of a PD programme [such as OER4Schools], the participating teachers' perceptions of national requirements pose a further constraint.

Some concerns are expressed in the interviews and workshops about the compatibility of the programme's approach with the national curriculum and Government policies that form the basis of school inspections. Several teachers felt uncomfortable about sharing learning objectives with pupils and unwilling to put this into practice.

PRISCILLAH: He was saying that we needed to tell the children the objectives because children should know what you as a teacher wants to achieve by the end of the day. [....] [However] if these people were to come, the inspectors, definitely they will question us, because it's something that is not done in our syllabus. They will simply say "But where did you get this from?"

Other teachers were, however, happy to implement all aspects of the programme (and facilitators upheld its principles); thus there remain some discrepancies in viewpoints - as there may be among teachers in the UK and elsewhere. National policy directives and school inspection regimes probably influence some pedagogical approaches and associated conceptions of learners and learning across most schools. In our study the underlying values of OER4Schools were made explicit and laid open to challenge within workshop discussions where teachers were free to express their divergent opinions.

In particular, there was quite a bit of disagreement, pedagogical and policy-related, on mixed-attainment grouping and debate about whether the approach was appropriate for all pupils, or in line with government requirements and inspection. It is interesting to note that mixed 'ability' groupings are now required by Zambian education policy and not solely something advocated by the OER4Schools programme; this change came in during our development period and teachers were aware. On the other hand the very discrepancies indicate that there is scope for different interpretations and movement.

Both head teachers interviewed held a positive view of the progressive outlook of the Ministry's aspirations. Cecilia asserted that inspectors would be pleased to find interactive teaching being implemented, since it was taught in colleges, "so when they find the pupils are making noise they will understand." They would be unhappy to see a rote learning lesson:

CECILIA: Inspectors will not accept [traditional teaching style], they would tell the teacher to improve on that. In fact ...they will tell the headteacher that he or she should make a follow-up to see that there is improvement.

DAVID: I don't think the Minister of Education would come and say, 'Now stop doing this', unless they want to be going backwards instead of going in front!

In practice, there were too few inspectors and Cecilia's school had not been inspected for several years, so the threat may have been less than that perceived by teachers. Moreover, it is 
important to note what is controlled by the Ministry, and what is in practice controlled locally:

DAVID: Mostly, that is the influence that the government has on our school - the curriculum and the teachers. The teaching method, mostly . . . comes from the teachers themselves after they have had to do their college [courses].

\section{Conclusions}

Using an ecological framework, supporting and constraining factors for introducing and sustaining pedagogic innovation in a low-resourced environment were characterised at three levels: teacher, school, and the wider community and policy context. The analysis is, in line with Davis' (2010) conception, not straightforwardly segmented since there are discussions of opportunities for change in the immediate classroom setting but in ways that also relate to the connections with the out-of-school lives of the children. There are further opportunities discussed that reportedly helped the teachers in dealing with both the school and national level challenges. Ultimately, then, there are some broader changes reported by these teachers about their own thinking that cut across the levels to some extent. These include teachers' changing views of the pupils and their capabilities, of their own capabilities, and their perceptions of the gap/connection between school and pupils' families/communities.

Rainio and Hofmann (2015), examining the emergence of new ways of dealing with problems of pupils' disengagement during a PD programme, discuss how the professional learning that took place during that programme was not pre-defined by the programme. The new heuristic and practical tools for thinking and teaching that supported the teachers in their professional learning and pedagogic change emerged through the teachers' collaborative and agentive engagement with the PD and, as a consequence of it, with each other. They have discussed how the support and change potential offered by such programmes may be latent rather than overt: such programmes may enable and frame certain practices and infrastructures and it is the process of the teachers' engagement with these that enables supporting factors for professional learning to emerge. We have, in this paper, described in detail several emerging latent supporting factors that played a role in this study and which we argue can be realistic across a range of settings.

At the classroom level, while the conditions for teaching and learning are very challenging, and initially posed difficulties for teachers' engagement in taking up the ideas from the PD programme, the programme appears to have also enabled the teachers to identify latent supporting factors within both their own classrooms - notably the pupils' capabilities and enthusiasm for trying new things - and the programme itself, which gave impetus to these new pedagogic ideas. Pedagogic changes at the classroom level are described by Hennessy et al. (forthcoming), and we remind readers that the OER4Schools programme content itself is freely available at www.oer4schools.org, and can be built upon or adapted to new country contexts. 


\section{Guidelines for implementing PD}

We conclude with a set of guidelines, to support the implementation of PD programmes, as well as to develop policy (Buckler, 2013). In order to implement the guidelines cost-effectively, they need to be embedded in policy, within national initiatives funded via both aid and government resources (such as SPRINT in Zambia). Some of the guidelines do not imply additional costs, but suggest an orientation for programmes. Indeed, the guidelines may help to avoid ineffective elements of programmes, and focus on more effective aspects instead. We also note that these guidelines are not meant to be complete or exhaustive: Sustainability is a multi-levelled complex notion, and for programmes to be sustainable, a range of other factors - beyond the scope of this discussion — need to be taken into account (we refer the reader to Haßler, Hennessy, \& Hofmann, with Makonga, in preparation). Moreover, policy change may be necessary to facilitate the smooth integration of digital technology throughout the school curriculum and in pre- and in-service teacher education programmes.

Programmes need to be long-term. Research demonstrates that change happens slowly, and that a programme needs to be sustained in order to lead to pedagogic change (Schwille, \& Dembélé, 2007).

Develop teacher agency and leadership. Programmes need to support professional growth of teachers over time, by encouraging not only their active participation in PD programmes and effective integration of new pedagogies, but their creation, adaptation and refinement of the programmes themselves. A shift from providing "off-the shelf" OER to creating locally contextualised and culturally embedded resources empowers teachers to become agents of change and innovation.

Focus on classroom implementation. Partly because teachers perceive the pedagogic ideas as repetition of what they have already been taught, but may not be actually (or fully) implementing them in practice, a focus on classroom implementation with sufficient scaffolding is necessary. Teachers may also believe that certain techniques are either irrelevant for practice or 'do not suit their pupils', which can likewise be challenged in this way. Overall, classroom implementation is essential in connecting theory and practice (confirming van Graan, et al., 2005).

\section{Create opportunities for collaboration with colleagues (within and outside} workshops). It is important to timetable structured opportunities for group discussion and reflection, e.g. to discuss the understanding of pedagogical ideas and classroom implementation (Schwille \& Dembélé, 2007). This also helps teachers understand ideas perceived as complex, and increases their level of interest. Because good workshop facilitation is an important mediator of professional learning, facilitators need to be chosen carefully, and support for facilitators is important.

\section{Draw on digital technology as a motivator for professional learning and pedagogic}


change. In our programme, digital technology is not only constructed as enhancing (teacher or pupil) learning, but also as a factor leveraging interactive pedagogies. Teachers are drawn in by (and introduced to) the technology, with the deliberate and explicit premise that effective use of technology depends on its interactive use. We have not undertaken a cost-benefit analysis, and there may well be other, more cost-effective motivational factors. It would nevertheless seem worth investigating what contribution the introduction of digital technology can make to teacher motivation.

However, if digital technologies are introduced for other reasons, it is essential to capitalise on this 'novelty' also as a motivational factor for pedagogic change. In particular, introducing digital technology per se first, and then addressing pedagogy later, is counterproductive. This shift (within a programme) from "technology focus" towards "pedagogic focus" needs to be made consciously, initially, and needs to be clearly structured, rather than expecting this to happen automatically. Otherwise the technology is assimilated into existing practices, without leading to higher quality learning outcomes (Kennewell, \& Beauchamp, 2007).

We illustrated how during the course of the programme the teachers did come to see that the pedagogic ideas of the programme were new - and implementable. They thereby came to see their own capabilities in new ways, partially mediated through digital technology use. This addressed, in part, the original constraints of seeing the pedagogic ideas as repetition, not fully understanding them and not perceiving them as feasible.

Encourage and scaffold teachers in obtaining resources. Emergently, teachers' own professional learning through the programme enabled them to address material shortages by accessing online resources and improvising, at least as a partial solution. Workshop facilitators helped teachers to see what resources might be available locally at no cost to substitute for implementation options that were inaccessible due to lack of funds. Whatever resources there are, do need to be used efficiently. From the teacher's perspective, the quantity of computers available is usually seen as a constraint, but this may overlook possibilities for "carousel group work", or more efficient timetabling. (In our study a small set of netbooks was shared by 12 classes.)

Encourage engagement with the local community. The programme enthused pupils, and it offered emergent support helping teachers to see their pupils' communities in new ways as a resource for learning. This challenges teachers' perceptions of (and some over-generalisations about) the disadvantaged communities they serve and the challenges they pose. Programmes should encourage teachers' awareness of the local community, as additional motivational and pedagogical support.

Make space for the programme within the school timetable (and adjust policy accordingly). Organisation of the school day (including teaching and management) can be a 
challenge, with conflicting priorities, not necessarily focussed on learning. Such diversity of focus (including many smaller programmes) means that there is little space for implementation of longitudinal, pedagogy-focussed programmes (Carter \& Richards, 1999). The space for such programmes should be created at the policy level; this is demonstrably possible. For instance, the SPRINT policy in Zambia provides a PD framework that schools and teachers are familiar with and sets an expectation of at least some professional learning time. Where teachers teach long hours during double shifts, however, they would need to be released from some teaching. Policy provision also needs to embed the principles of interactive teaching at national level, and thereby support implementation at school level; in this way, the OER4Schools programme constitutes one possible implementation of SPRINT. Through adequate policy provision (and implementation), (perceived) restrictions of national curriculum and (perceived) risks due to inspections can be countered.

While our research shows evidence for change towards greater quality teaching and learning, both in the classroom (Hennessy et al., forthcoming), and in teacher PD (this paper), the question of sustainability and scalability needs to be addressed. This includes the wider rollout of the programme to other schools in Zambia and indeed elsewhere. For this, an effective network of teachers and headteachers at local, district, and regional level is needed, supporting each other in implementing a programme such as OER4Schools. This is not a trivial task, especially given that our data clearly show that face-to-face contact and a degree of external support are initially beneficial. The pre-existing SPRINT programme facilitates sustainability and growth of OER4Schools in Zambia, and such in-service professional development initiatives may provide models for use elsewhere. The question of sustainability is the subject of a forthcoming article by Haßler et al. (in preparation), which also gives further details of the continued, self-sustaining peer facilitation of the programme, running in CBS with negligible input from us and little funding since 2012. Discussions with the Zambian Ministry of Education are currently underway about expanding the programme from 2015 onwards. Since the start of the programme, a number of teachers have been transferred to other schools, and have continued using OER4Schools, as well as engaging other colleagues. The lead facilitator of the programme has also conducted workshops at other schools and for a local non-governmental organisation, partially adapting the resource for new contexts. There is interest in the programme from Kenya, Rwanda, Sierra Leone and Uganda, with some exploratory activities underway to provide the teacher development component of ongoing or forthcoming technology initiatives. Re-contextualisation of OER4Schools has already been done for Kenya by a Kenyan teacher in-country and it is in progress by the Rwandan Education Board in conjunction with the One-Laptop-Per-Child scheme that is well-established in that country.

\section{Acknowledgements}


We are most grateful to the teachers and the school who participated in our trials for their enthusiasm and support. Thanks also to Masters students Andrew Cross and Melissa Marsden for their roles in the data collection and analysis. The OER4Schools programme was based in the University of Cambridge Centre for Commonwealth Education (CCE) and was supported by the Commonwealth Education Trust, primarily funding the creation of the resource and the research. We greatly appreciate the administrative support provided by various CCE staff throughout the programme.

\section{References}

Anamuah-Mensah, J., Banks, F., Moon, B., \& Wolfenden, F. (2013). New Modes of Teacher Pre-service Training and Professional Development. In B. Moon (Ed.), Teacher Education and the Challenge of Development: a Global Analysis (pp. 201-211). New York: Routledge.

Avalos, B. (2011). Teacher professional development in Teaching and Teacher Education over ten years. Teaching and Teacher Education, 27, 10-20. doi:10.1016/j.tate.2010.08.007

Borko, H. (2004). Professional Development and Teacher Learning: Mapping the Terrain. Educational Researcher, 33, 3-15. doi:10.3102/0013189X033008003

Bransford, J., \& Schwartz, D. (1999). Rethinking transfer: A simple proposal with multiple implications. Review of Research in Education, 24, 61-100. doi:10.3102/0091732X024001061

Buckler, A., \& Gafar, A. I. A. (2013). Professional Development and Female Teacher Morale in Rural Communities. In B. Moon (Ed.), Teacher Education and the Challenge of of Development: a Global Analysis (pp. 115-128). New York: Routledge.

Carter, R., \& Richards, J. (1999). Dilemmas of constructivist mathematics teaching: Instances from classroom practice. In B. Jaworksi, T. Wood, \& S. Dawson (Eds.), Mathematics Teacher Education: Critical International Perspectives (pp. 69-77). London: Falmer Press.

Cordingley, P., Rundell, B., Temperey, J., \& McGregor, J. (2004). From transmission to collaborative learning: Best evidence in continuing professional development (CPD). Paper presented at the International Congress for School Effectiveness and Improvement (ICSEI), Rotterdam, The Netherlands.

Davis, N. (2010). Global interdisciplinary research into the diffusion of IT innovations in education. In A. McDougall, J. Murnane, A. Jones, \& N. Reynolds (Eds.), Researching IT in education: theory, practice and future directions (pp. 142-150). Abingdon: Routledge. 
Retrieved from http://www.routledge.com/books/details/9780415560009/

Guskey, T. R. (1989). Attitude and perceptual change in teachers. International Journal of Educational Research, 13, 439-453. doi:10.1016/0883-0355(89)90039-6

Haßler, B., Hennessy, S. \& Cross, A. with Chileshe, E. and Machiko, B. (2014). School-based professional development in a developing context: Lessons learnt from a case study in Zambia. Professional Development in Education.

Haßler, B., Hennessy, S., \& Hofmann, R., with Makonga, A. (in preparation). Sustainability and scalability of pedagogic innovation in sub-Saharan Africa: The case of the OERS4Schools professional development programme.

Haßler, B., Hennessy, S., Lord, T., Cross, A., Jackson, A., \& Simpson, M. (2011). An investigation of appropriate new technologies to support interactive teaching in Zambian schools (ANTSIT). A joint report from Aptivate and the Centre for Commonwealth Education (University of Cambridge). Final Report to DfID. Cambridge: Aptivate and University of Cambridge. Retrieved from http://www.educ.cam.ac.uk/centres/cce/initiatives/projects/antsit/.

Haßler, B., Hennessy, S., \& Lubasi, B. (2011). Changing classroom practice using a school-based professional development approach to introducing digital resources in Zambia. Itupale Online Journal of African Studies, 3, 17-31.

Haßler, B., \& Mays, T. (2014). Open Content. In P. Hwa Ang \& R. Mansell (Eds.), International Encyclopedia of Digital Communication and Society. Wiley-Blackwell. Retrieved from http://bjohas.de/Publications/Hassler_Mays_OpenContent.

Hennessy, S., Haßler, B., \& Hofmann, R. (forthcoming). Pedagogic change by Zambian primary school teachers participating in the OERS4Schools professional development programme for one year.

Hennessy, S., Haßler, B., \& Mwewa, G. (2012). Using digital technology and school-based professional development to leverage interactive classroom teaching in Zambia. In J. MacBeath, M. Younger, \& C. Sugrue (Eds.), Millennium Goals Revisited: A Common Wealth of Learning. London: Routledge.

Hennessy, S., Onguko, B., Ang'ondi, E. K., Harrison, D., Namalefe, S., Naseem, A., \& Wamakote, L. (2010). Developing use of ICT to enhance teaching and learning in East African schools: a review of the literature (No. 1). Cambridge, UK and Dar es Salaam, TZ: Faculty of Education, University of Cambridge and Aga Khan University Institute for Educational Development - Eastern Africa.

Kennewell, S., \& Beauchamp, G. (2007). The features of interactive whiteboards and their 
influence on learning. Learning, Media and Technology, 32, 227-241.

doi:http://dx.doi.org/10.1080/17439880701511073

Leu, E. (2004). The patterns and purposes of school-based and cluster teacher professional development programs. Issues Brief, 1. Retrieved from

http://www.equip123.net/docs/working-p2.pdf

Mazala, Chileya Mbasilu. (2011). The effects of continuing professional development (CPD) though sprint on teacher classroom practices and student learning outcomes (Thesis). Retrieved from http://dspace.unza.zm:8080/jspui/handle/123456789/415

Moon, B. (2007). Research analysis: Attracting, developing and retaining effective teachers: A global overview of current policies and practices. Paris: UNESCO.

Moon, B. (2007, September). The Global Teacher Crisis meeting the challenge through new technologies and new modes of teaching and learning. Paper presented at the 12th Cambridge International Conference on Open and Distance Learning, Cambridge, UK. Retrieved from http://ebookbrowsee.net/bobmoonkeynotepresentationcambridge2007-pptd373579301

Mubanga, R. (2012). School Program of In-service Training for the Term (SPRINT) Programme in Zambia -A Case of Collaboration Towards Self-Reliant Education Development. Paper presented at Japan Education Forum IX, Tokyo, Japan. Retrieved from http://home.hiroshima-u.ac.jp/cice/wp-content/uploads/Forum/JEF9/Ruth-Mubanga-e.pdf

Mwale, Kelly Kezala. (2011). Provision of continuing professional development by resource centres in selected high schools of the Copperbelt province (Thesis). Retrieved from http://dspace.unza.zm:8080/jspui/handle/123456789/482

Mwansa, P. (2011). Implemantation of the school programme of in service for the term (SPRINT) in selected basic schools of Chipata district of Zambia (Thesis). Retrieved from http://dspace.unza.zm:8080/jspui/handle/123456789/3322

Naseem, A. (2011, May). Teacher professional development through blended approaches: A way forward for sub-Saharan Africa. Paper presented at the eLearning Africa 2011: 6th International Conference on ICT for Development, Education and Training, Aga Khan University, Pakistan.

OECD. (2005). Teachers Matter: Attracting, Developing and Retaining Effective Teachers (Research Report No. 9264018026). Retrieved from OECD website: http://www.oecd.org/edu/school/attractingdevelopingandretainingeffectiveteachersfinalreportteachersmatter.htm

Power, T. (2013). The "New" New Technology: Exploiting the Potential of Mobile 
Communications and Open Educational Resources. In B. Moon (Ed.), Teacher Education and the Challenge of of Development: a Global Analysis (pp. 212-226). New York:

Routledge.

Rainio, A. P., \& Hofmann, R. (2015). Transformations in teachers' discourse about their students during a school-led pedagogic intervention. The European Journal of Social \& Behavioural Sciences XIII (2), pp. 1815-1829.

Schwille, J., \& Dembélé, M. (2007). Global perspectives on teacher learning: improving policy and practice. Paris: International Institute for Educational Planning.

Sichaaza, Metto Muzyamba. (2011, June). Continuing professional development of community school teachers: A case study of Sinazongwe District (Thesis). Retrieved from http://dspace.unza.zm:8080/jspui/handle/123456789/520

Somekh, B. (2010). The practical power of theoretically-informed research into innovation. In A. McDougall, J. Murnane, A. Jones, \& N. Reynolds (Eds.), Researching IT in education: theory, practice and future directions (pp. 129-141). Abingdon: Routledge. Retrieved from http://www.routledge.com/books/details/9780415560009/

Tillman, L. C. (2006). Researching and writing from an African-American perspective: reflective notes on three research studies. International Journal of Qualitative Studies in Education, 19, 265-287. doi:10.1080/09518390600696513

UNESCO. (2014). Teaching and learning: achieving quality for all. Paris, France: UNESCO Publishing. Retrieved from http://www.unesco.org/new/en/education/themes/leading-theinternational-agenda/efareport/reports/2013/

Van Graan, M., Pomuti, H., LeCzel, D., Liman, M., \& Swarts, P. (2005). Practicing Critical Reflection in Teacher Education in Namibia (Report No. 92-9178-058-8). Paris, France: ADEA (Association for the Development of Education in Africa).

Walsh, C., \& Power, T. (2011, November). Going digital on low-cost mobile phones in Bangladesh. Paper presented at the Annual International Conference on Education \& eLearning (EeL), Singapore. Retrieved from http://www.eiabd.com/eia_oldsite/file_zone/publications/conf_papers/Walsh,Power-2011Going_digital_on_low-cost_mobile_phones_in_Bangladesh.pdf

Westbrook, J., Durrani, N., Brown, R., Orr, D., Pryor, J., Boddy, J., \& Salvi, F. (2013). Pedagogy, curriculum, teaching practices and teacher education in developing countries Final report. Education Rigorous Literature Review. (EPPI-Centre reference number 2110). Retrieved from https://eppi.ioe.ac.uk/cms/Default.aspx?tabid=3433

Zhao, Y., \& Cziko, G. A. (2001). Teacher adoption of technology: A perceptual- control-theory 
perspective. Technology and Teacher Education, 9, 5-30. 